Berkala Ilmu Perpustakaan dan Informasi, Vol. 13, No. 2, Desember 2017, Hal. 107-116 DOI: 10.22146/bip.23453

ISSN 1693-7740 (Print), ISSN 2477-0361 (Online)

Tersedia online di https://jurnal.ugm.ac.id/bip

\title{
PENERAPAN SISTEM KLASIFIKASI PERPUSTAKAAN ARKEOLOGI DI PERPUSTAKAAN BALAI ARKEOLOGI DAERAH ISTIMEWA YOGYAKARTA
}

\author{
Bayu Indra Saputro ${ }^{1}$ \\ ${ }^{1}$ Pustakawan Balai Arkeologi Daerah Istimewa Yogyakarta \\ email : bayu.library@gmail.com
}

Naskah diterima: 30 Maret 2017, direvisi: 25 September 2017, disetujui: 30 Oktober 2017

\begin{abstract}
ABSTRAK
Pengorganisasian bahan pustaka di perpustakaan tidak lepas dari penerapan sistem klasifikasi yang digunakan sebagai penentuan kelas dalam penjajaran koleksi di rak. Penjajaran yang sistematis akan memudahkan pustakawan dan pemustaka dalam temu kembali koleksi di perpustakaan. Penerapan Sistem Klasifikasi Perpustakaan Arkeologi (SPKA) di perpustakaan Balai Arkeologi Daerah Istimewa Yogyakarta sudah dilakukan sejak tahun 1994. Untuk itu penulis mencoba melakukan penelitian penerapan sistem klasifikasi tersebut menggunakan metode deskriptif dengan pendekatan kualitatif. Dalam penelitian tersebut didapatkan beberapa kendala yaitu, pembagian kelas utama yang tumpang tindih, pembagian subkelas yang tidak tepat, pengklasifikasian yang tidak konsisten, munculnya nomor klasifikasi baru, perubahan subyek kelas utama yang tidak tepat, serta hilangnya beberapa subkelas dalam penerapan sistem klasifikasi tersebut. Semua itu dapat diatasi jika classifer mampu mengklasifikasi bahan pustaka dengan konsistensi pada bagan Sistem Klasifikasi Perpustakaan Arkeologi yang sudah disepakati. Selanjutnya,untuk mengatasi perkembangan disiplin ilmu arkeologi perlu penerapan bagan Sistem Klasifikasi Perpustakaan Arkeologi yang baru.
\end{abstract}

Kata Kunci: Arkeologi; Klasifikasi; Balai Arkeologi D.I Yogyakarta

\section{ABSTRACT}

Organising materials in is a main aspect in the implementation of the library classification system. The system makes it easier for librarians and users to retrieve the materials. Sistem Klasifikasi Perpustakaan Arkeologi (SPKA) in the library of Balai Arkeologi Daerah Istimewa Yogyakarta has been applied since 1994. Using a descriptive method with qualitative approach, the paper examines the application of the system in the library. The results show that challenges emerged including overlapping major classes, improper subclass division, classification inconsistencies, the emergence of new classification numbers, inaccurate primary class changes, and the disappearance of several subclasses in the system. These can be solved if a classifer does her job consistently based on the SPKA. It is also necassary to have a new system due to the development of archeological sciences.

Keywords: Archeology; Classifications; Balai Arkeologi D.I Yogyakarta

\section{A. PENDAhULUAN}

Kegiatan yang tidak dapat dipisahkan dari pengorganisasian bahan perpustakaan adalah temu kembali. Secara terminologis, sistem temu kembali adalah suatu sistem di mana sebuah informasi disimpan dan ditemukan kembali. Sebagai suatu sistem, informasi tersebut disimpan dan disusun dalam satu pengelompokkan yang saling berinteraksi, dan masing-masing memenuhi fungsi khusus untuk mencapai tujuan khusus.

Menurut Lancester dalam (Abd Rohim, 2010), sistem temu kembali informasi tidak memberitahu pemustaka atas subyek yang dimintanya. Sistem tersebut hanya menginformasikan atas keberadaan atau 
ketiadaan dan di mana koleksi atas permintaanya tersebut berada.

Konsep dari sistem temu kembali mensyaratkan adanya beberapa koleksi atau dokumen yang mengandung informasi dan dikelompokkan menurut subyek dari koleksi atau dokumen tersebut ke dalam satu kelompok yang sama. Sistem temu kembali informasi haruslah memuat data bibliografis koleksi yang ada sehingga pemustaka dapat menelusur dengan cepat dan tepat. Oleh karena itu beberapa ahli temu kembali informasi menciptakan alat yang dapat mengelompokkan subyek koleksi sesuai dengan subyek yang sama.

Menurut (Hamakonda, 2006), alat yang diciptakan untuk mengelompokkan subyek dan memaksimalkan temu kembali informasi adalah sistem klasifikasi. Memilih sistem klasifikasi yang tepat sebagai alat temu kembali informasi bahan pustaka atau informasi merupakan hal yang penting bagi perpustakaan. Hal ini bermanfaat bagi pemustaka dalam mendapatkan informasi yang dibutuhkan. Di samping itu pemilihan sistem klasifikasi yang tepat juga memudahkan pustakawan dalam mengorganisir bahan pustaka.

Perpustakaan instansi Balai Arkeologi D.I Yogyakarta merupakan perpustakaan khusus yang bertujuan mendukung pelaksanaan program pendidikan/pengajaran dan penelitian, serta menyediakan bahan pustaka referensi arkeologi, baik dalam bentuk buku maupun kolesi lainnya yang berfungsi sebagai ilmu bantu, untuk diajarkan, dipelajari, dan dikembangkan lebih lanjut(Widodo, 1994).

Sesuai dengan tugas dan fungsi di atas, Perpustakaan Balai Arkeologi D.I Yogyakarta memberikan layanan informasi, melakukan pengadaan bahan pustaka referensi arkeologi sesuai dengan kebutuhan peneliti, serta melakukan pengolahan bahan pustaka. Agar dapat mengoptimalkan penelusuran bahan pustaka tersebut secara cepat dan tepat, maka pustakawan melakukan pengolahan bahan pustaka, yang meliputi inventarsasi, klasifikasi, labeling, input data ke komputer, penyajian Onlie Public Acces Cataloging (OPAC), dan penataan koleksi ke rak.
Untuk mempermudah pemustaka dalam melakukan temu kembali informasi, pustakawan harus memperhatikan dalam menerapkan sistem klasifikasi yang digunakan. Sistem klasifikasi memberikan kemudahan kepada pemustaka dalam memilih informasi yang dibutuhkan secara cepat dan tepat. Suatu sistem klasifikasi pada dasarnya menyediakan daftar notasi yang disertai subjeknya dan berbagai ketentuan yang menyangkut mekanisme pembentukan notasi dan penelusurannya.

Pada umumnya perpustakaan menggunakan klasifikasi DDC atau UDC yang sudah lazim digunakan di perpustakaan Indonesia. Tetapi di Perpustakaan Balai Arkeologi D.I Yogyakarta, sampai saat ini menggunakan Sistem Klasifikasi Perpustakaan Arkeologi (SKPA) yang dibuat pustakawan Balai Arkeologi D.I Yogyakarta. Tujuan penyusunan sistem klasifikasi tersebut adalah untuk mengakomodir pengelompokan koleksi yang ada secara sederhana. Bagan Sistem Klasifikasi Perpustakaan Arkeologi ini mengelompokkan bahan pustaka tidak hanya dengan menelaah subyek atau disiplin ilmu yang ada, tetapi juga pada jenis koleksi yang akan diklasifikasi.

Pada forum Evaluasi Hasil Penelitian Arkeologi di Palembang pada tanggal $11-16$ Oktober 1994, dipaparkan Sistem Klasifikasi Perpustakaan Arkeologi yang digunakan oleh Perpustakaan Balai Arkeologi D.I Yogyakarta, yang kemudian juga diterapkan pada 9 (sembilan) Balai Arkeologi lainnya. Dalam kurun waktu 1994 hingga sekarang banyak kendala dalam pengklasifikasian koleksi yang berkaitan dengan ilmu arkeologi. Dengan perkembangan subyek ilmu arkeologi yang semakin pesat dan jenis koleksi di perpustakaan, maka terdapat ketidak konsistensian dalam pemberian nomor klasifikasi pada koleksi tersebut. Sampai sekarang penelitian dan evaluasi tentang Sistem Klasifikasi Perpustakaan Arkeologi belum dilakukan oleh pustakawan di instansi Balai Arkeologi.

Sehubungan dengan itu, penulis mencoba mengkaji perkembangan, kendala, dan relevansi ke depan dalam penggunaan Sistem Klasifikasi Perpustakaan Arkeologi di Perpustakaan Balai 
Arkeologi D.I Yogyakarta. Hal ini juga sebagai bentuk pengenalan Sistem Klasifikasi Perpustakaan Arkeologi kepada pemustaka yang tidak terbiasa dengan sistem klasifikasi tersebut.

\section{B. TINJAUAN PUSTAKA Definisi Sistem Klasifikasi}

Sistem pengelompokan/klasifikasi koleksi dapat berdasarkan pada jenis, ukuran (tinggi, pendek, besar, kecil, dll), warna, abjad judul, dan abjad pengarang. Namun sebagian besar perpustakaan menggunakan sistem pengelompokan koleksi berdasarkan subjek bahan pustaka.

Sistem klasifikasi itu sendiri adalah sistem pengelompokan sistematis dari sejumlah objek, gagasan, buku atau benda-benda lain ke dalam kelas atau golongan tertentu berdasarkan ciriciri yang sama(Hamakonda, 2006).

Sedangkan menurut Yusup dan Suhendar (2005), klasifikasi adalah penggolongan atau pengelompokan buku berdasarkan subyek atau isi bahan pustaka yang ada.

Dari definisi di atas sistem klasifikasi adalah penggolongan sejumlah objek, gagasan, buku atau benda-benda lain berdasarkan subyek atu ciri-ciri yang sama agar dalam penyusunannya dapat teratur sesuai dengan kesamaan subyeknya dan saling berdekatan letaknya, sedangkan subyek yang berbeda akan ditempatkan terpisah atau berjauhan. Kegiatan pengelompokan ini akan memudahkan pemustaka dalam temu kembali informasi.

Menurut (Suwarno, 2007), secara umum klasifikasi terbagi ke dalam dua jenis, yaitu :

a. Klasifikasi artifisial, yaitu klasifikasi bahan pustaka berdasarkan sifat-sifat yang kebetulan ada pada bahan pustaka tersebut. Misalnya tinggi buku atau warna buku.

b. Klasifikasi fundamental, yaitu klasifikasi bahan pustaka berdasarkan isi atau subjek buku pada bahan pustaka tersebut.

Sedangkan menurut (Sutarno, 2006), klasifikasi terdiri atas :

a. Klasifikasi sederhana, yaitu klasifikasi yang notasinya ditentukan maksimal 5 angka. Sistem in biasanya diterapkan pada perpustakaan dengan koleksi sedikit atau terbatas.

b. Klasifikasi kompleks, yaitu klasifikasi yang notasinya mewakili isi bahan pustaka secara spesifik atau setepat mungkin.

Dalam perkembangan selanjutnya, sistem klasifikasi subjek ada yang menggunakan notasi/tanda berupa huruf dan angka. Sebagai contoh sistem klasifikasi dengan menggunakan notasi/tanda huruf dan angka adalah sebagai berikut ini :

a. Huruf

Sistem notasi yang lazim dalam menggunakan tanda huruf terdapat pada Sistem Klasifikasi Perpustakaan Kongres / Library of Congress System. Sistem itu digunakan oleh Perpustakaan Kongres Amerika Serikat yang saat itu menggunakan sitem ukuran dokumen, seperti folio, kuarto, dll.

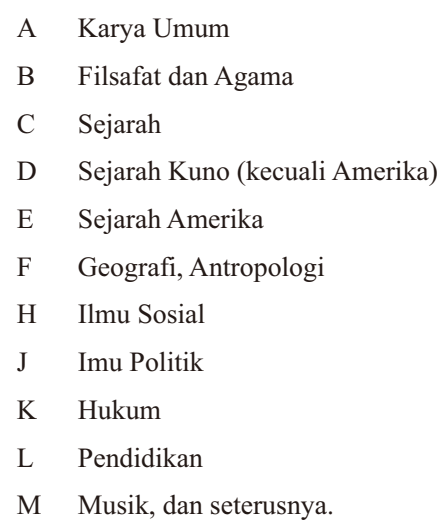

b. Angka

Sistem klasifikasi dengan menggunakan notasi angka, antara lain, tedapat dalam Sistem Klasifikasi Persepuluhan Universal / Universal Decimal Classification System (UDC) dan Sistem Klasifikasi Persepuluhan Dewey/Dewey Decimal Classification System (DDC).

Sistem klasifikasi DDC adalah sebuah sistem klasifikasi perpustakaan yang diciptakan oleh Melvil Louis Kossuth Dewey pada tahun 1873 dan pertama kali diterbitkan pada tahun 1976, yaitu sebuah pamflet yang berjudul $A$ Classification and Subject Index for Cataloging and Arrangging the Books and Pamphlets of a Library. Edisi pertama diterbitkan dengan memuat kata pendahuluan, bagan untuk 10 kelas utama yang dibagi secara desimal menjadi 1000 kategori bernomor 000-900, serta indeks subjek 
berabjad, dan sejak saat itu telah banyak dimodifikasi dan terus dikembangkan hingga muncul DDC Edisi 23.

Menurut Masruri (2006), sistem klasifikasi Dewey Decimal Calssification (DDC) merupakan klasifikasi berdasarkan disiplin ilmu, bukan hanya pengelompokan koleksi berdasarkan subjek. Pembagian kelas utama dan subkelas berdasarkan disiplin akademis atau bidang kajian, bukannya berdasarkan subjek. Hasilnya dimungkinkan subjek yang sama memperoleh tempat kelas dari satu. Misalnya subjek keluarga mungkin digolongkan ke dalam kelas sosiologi, agama, etika, hukum, dan lain sebagainya.

DDC dibagi ke dalam 10 kelas utama (The Ten Main Classes) atau First Summary dengan menggunakan angka-angka persepuluhan. Sepuluh kelas utama diberi nomor urut $0,1,2,3$, $4,5,6,7,8,9$. Tetapi dalam prakteknya selalu dituliskan dalam bentuk notasi dengan tiga bilangan dan tidak boleh kurang.

$\begin{array}{ll}000-099 & \text { Generalitis (Karya Umum) } \\ 100-199 & \text { Philosophy \& Psychology (Filsafat dan Psikologi) } \\ 200-299 & \text { Religion (Agama) } \\ 300-399 & \text { Social Science (Ilmu-Ilmu Sosial) } \\ 400-499 & \text { Languange (Bahasa) } \\ 500-599 & \text { Natural Sciences and Mathematics (Ilmu-Ilmu } \\ & \text { Alam dan Matematika) } \\ 600-699 & \text { Technology and Applied Science (Ilmu } \\ & \text { Pengetahuan Terapan dan Teknologi) } \\ 700-799 & \text { The Art, Fine and Sport (Kesenian, Hiburan, dan } \\ & \text { Olahraga) } \\ 800-899 & \text { Literature and Rhetoric (Kesusasteraan) } \\ 900-999 & \text { Geography and History (Geografi dan Sejarah) }\end{array}$

Tiap-tiap kategori di atas, dibagi ke dalam sembilan sub kategori (divisi). Misalnya untuk kelas 900 adalah sebagai berikut :

\begin{tabular}{|c|c|}
\hline $900-909$ & Theory of History (Teori Ilmu Sejarah) \\
\hline $910-919$ & Geography and Travel (Geografi dan Perjalanan) \\
\hline $920-929$ & Geography and Genealogy (Biografi dan Silsilah) \\
\hline $930-939$ & $\begin{array}{l}\text { History of Ancient World to } 499 \text { (Sejarah Dunia } \\
\text { Kuno sampai dengan Tahun 499) }\end{array}$ \\
\hline $940-949$ & General History of Europe (Sejarah Umum Eropa) \\
\hline $950-959$ & General History of Asia (Sejarah Umum Asia) \\
\hline $960-969$ & General History of Africa (Sejarah Umum Afrika) \\
\hline $970-979$ & $\begin{array}{l}\text { General History of North America (Sejarah Umum } \\
\text { Amerika Utara) }\end{array}$ \\
\hline $980-989$ & $\begin{array}{l}\text { General History of South America (Sejarah Umum } \\
\text { Amerika Selatan/Amerika Latin) }\end{array}$ \\
\hline $990-999$ & $\begin{array}{l}\text { General History of Other Parts of Wrld (Sejarah } \\
\text { Umum Bagian Dunia Lainnya) }\end{array}$ \\
\hline
\end{tabular}

Selanjutnya, tiap-tiap divisi dapat dibagi lagi menjadi seksi. Misalnya untuk kelas 900 perinciannya adalah sebagai berikut :
History, Events (Ilmu Sejarah, Kejadian) Philosopy and Theory of History (Filsafat dan Teori Sejarah)

Miscellany of History (Aneka Ragam Sejarah) Dictionary and Encyclopedia (Kamus, Sejarah, Ensiklopedia Sejarah)

903

904

905

Collected Accounts of Events

(Petualangan, Kumpulan Peristiwa Tertentu)

Serial Publications o f History (Terbitan Berseri di Bidang Sejarah)

906 Organization an Management of History (Organisasi dan Manajemen di Bidang Sejarah)

907

909

Education and Research of History (Pendidikan,

Riset Penelitian Sejarah)

World History, Civilizations (Sejarah Dunia, Peradaban)

909.4 History of Racial, Ethnic Groups (Sejarah Berdasarkan Ras dan Etnis)

909.041 History of race of Indonesia (Sejarah Ras-ras dan Suku-suku di Indonesia)

909.07 History of Middle Ages (Sejarah Dunia pada Peradaban Pertengahan)

909.1 World History 6th - 12th Century, $500-1199$

(Sejarah Dunia Abad 6 - 12, Tahun 500 - 1199)

World History 13th Century, 1200 - 1299

(Sejarah Dunia Abad 13, Tahun 1200 - 1299)

909.3 World History 14th Century, 1300 - 1399, 1300

- 1399 (Sejarah Duni a Abad 14, Tahun 1300 1399)

909.4 World History 15th Century, 1400 - 1499

(Sejarah Dunia Abad 15, Tahun 1400 - 1499)

909.5 World History 16th Century, $1500-1599$

(Sejarah Dunia Abad 16, Tahun 1500 - 1599)

909.6 World History 17th Century, $1600-1699$

(Sejarah Dunia Abad 17, Tahun 1600 - 1699)

909.7 World History 18th Century, 1700 - 1799

(Sejarah Dunia Abad 18, Tahun 1700 - 1799)

909.81 World History 19th Century, 1800 - 1899

(Sejarah Dunia Abad 19, Tahun 1800 - 1899)

909.82 World History 20th Century, $1900-1999$

(Sejarah Dunia Abad 20, Tahun 1900 - 1999)

World History 21th Century, 2000 - 2999

(Sejarah Dunia Abad 21, Tahun 2000 - 2999)

\section{Definisi Sistem Klasifikasi Perpustakaan Arkeologi}

Pada forum Evaluasi Hasil Penelitian Arkeologi di Palembang pada tanggal $11-16$ Oktober 1994, dipaparkan Sistem Klasifikasi Perpustakaan Arkeologi yang terdiri dari 14 (empat belas) kelas utama (Tabel 1).

Tabel 1.Bagan Kelas Utama Sistem Klasifikasi Perpustakaan Arkeologi

\begin{tabular}{ll}
\hline 01 & Arkeologi Prasejarah \\
02 & Arkeologi Klasik \\
03 & Arkeologi Islam \\
04 & Arkeometri \\
05 & Etnoarkeologi \\
06 & Studi Kasus \\
07 & Metode/Teori \\
08 & Kebudayaan \\
09 & Penerbitan Berkala \\
10 & Referensi \\
11 & Kumpulan Makalah \\
12 & Sejarah \\
13 & Laporan \\
14 & Kedinasan \\
\hline & Sumber: Kumpulan Makalah EHPA Palembang, 11- \\
& 16 Oktober 1994
\end{tabular}


Di dalam bagan SPKA pembagian sub-sub kelas dari kelas utama (Tabel 2).

Pada dasarnya pembuatan klasifikasi yang diadopsi oleh Perpustakaan Balai Arkeologi D.I Yogyakarta hampir mirip dengan penjabaran subyek atau disiplin ilmu pada sistem klasifikasi DDC.

Penetapan nomor kelas pada Sistem Klasifikasi Perpustakaan Arkeologi berdasarkan pada ruang lingkup subyek arkeologi dan sejarah serta jenis koleksi yang ada. Pada sistem klasifikasi tersebut ilmu arkeologi dibagi menjadi tiga bidang kajian utama, yaitu Arkeologi Prasejarah (kelas 01), Arkeologi Klasik (kelas 02), dan Arkeologi Islam-Kolonial (kelas 03). Sedangkan untuk pengelompokan kelas lainnya dipakai untuk bidang Arkeometri (kelas 04), Etnoarkeologi

(kelas 05), Studi Kasus (kelas 06), Teori (kelas 07), dan Kebudayaan (kelas 08). Sedangkan kelas utama selanjutnya dikelaskan menurut jenis koleksi, yaitu Penerbitan Berkala (kelas 09), Referensi (kelas 10), Kumpulan Makalah (kelas 11), Sejarah (kelas 12), Laporan (kelas 13) dan Kedinasan (kelas 14). Sedangkan pembagian subkelas merupakan hasil dari penjabaran disiplin ilmu arkeologi dan juga jenis dari koleksi yang ada di perpustakaan. Pembagian kelas ini dianggap mampu mengakomodir pengklasifikasian koleksi bahan pustaka secara mudah dan efektif pada waktu itu.

Cara penggunaan SKPA pada dasarnya sama dengan sistem klasifikasi lainnya yaitu dengan memperhatikan subyek atau disiplin ilmu yang ada pada koleksi bahan pustaka serta jenis bahan pustaka sesuai dengan pembagian bagan klasifkasi tersebut. Prinsip dari penentuan nomor SKPA adalah sebagai berikut:

a. Menelaah subyek atau disiplin ilmu bahan pustaka atau jenis koleksi yang akan diklasifikasi.

b. Penentuan nomor klasifikasi sesuai dengan bagan klasifikasi.

c. Apabila terdapat subyek disiplin ilmu yang masuk ke dalam dua nomor, maka harus dilihat subyek mana yang paling dominan.
Tabel 2.Subkelas pada bagan Sistem Klasifikasi Perpustakaan Arkeologi

\begin{tabular}{|c|c|c|}
\hline \multirow[t]{7}{*}{01} & \multicolumn{2}{|c|}{ Arkeologi Prasejarah } \\
\hline & 01.1 & Arsitektur \\
\hline & 01.2 & Pemukiman \\
\hline & 01.3 & Religi \\
\hline & 01.4 & Sosial Ekonomi \\
\hline & 01.5 & Teknologi \\
\hline & 01.6 & Ikonografi \\
\hline \multirow[t]{9}{*}{02} & \multicolumn{2}{|c|}{ Arkeologi Klasik } \\
\hline & 02.1 & Arsitektur \\
\hline & 02.2 & Pemukiman \\
\hline & 02.3 & Religi \\
\hline & 02.4 & Sosial Ekonomi \\
\hline & 02.5 & Teknologi \\
\hline & 02.6 & Epigrafi \\
\hline & 02.7 & Ikonografi \\
\hline & 02.8 & Kesenian \\
\hline \multirow[t]{8}{*}{03} & \multicolumn{2}{|c|}{ Arkeologi Islam - Kolonial } \\
\hline & 03.1 & Arsitektur \\
\hline & 03.2 & Pemukiman \\
\hline & 03.3 & Religi \\
\hline & 03.4 & Sosial Ekonomi \\
\hline & 03.5 & Teknologi \\
\hline & 03.6 & Epigrafi \\
\hline & 03.7 & Kesenian \\
\hline 04 & Arke & \\
\hline 05 & Etno & \\
\hline 06 & Stud & \\
\hline 07 & Meto & \\
\hline \multirow[t]{9}{*}{08} & Kebu & \\
\hline & 08.1 & Peradaban Dunia \\
\hline & 08.2 & Kalimantan \\
\hline & 08.3 & Sunda, Bali, Jakarta \\
\hline & 08.4 & Indonesia Timur \\
\hline & 08.5 & Jawa, Madura \\
\hline & 08.6 & Sulawesi \\
\hline & 08.7 & Sumatra \\
\hline & 08.8 & Indonesia Umum \\
\hline \multirow[t]{3}{*}{09} & \multicolumn{2}{|c|}{ Penerbitan Berkala } \\
\hline & 09.1 & Bidang Arkeologi \\
\hline & 09.2 & Bidang Ilmu Bantu \\
\hline \multirow[t]{8}{*}{10} & \multicolumn{2}{|c|}{ Referensi } \\
\hline & 10.1 & Kamus \\
\hline & 10.2 & Ensiklopedi \\
\hline & 10.3 & Majalah Arkeologi (VKI, BKI) \\
\hline & 10.4 & Skripsi, Tesis, Disertasi \\
\hline & 10.5 & $\begin{array}{l}\text { Laporan Hasil Penelitian Arkeologi } \\
\text { (OV, OJO, ROD) }\end{array}$ \\
\hline & 10.6 & Kliping \\
\hline & 10.7 & Lain-Lain \\
\hline \multirow[t]{8}{*}{11} & \multicolumn{2}{|c|}{ Kumpulan Makalah } \\
\hline & 11.1 & PIA \\
\hline & 11.2 & AHPA \\
\hline & 11.3 & REMPA \\
\hline & 11.4 & EHPA \\
\hline & 11.5 & REHPA \\
\hline & 11.6 & DIA \\
\hline & 11.7 & Lain-Lain \\
\hline 12 & Sejar & \\
\hline \multirow[t]{2}{*}{13} & Lapo & \\
\hline & 13.1 & Berita Penelitian Arkeologi \\
\hline 14 & Kedi & \\
\hline
\end{tabular}

Sumber: Kumpulan Makalah EHPA Palembang, 11 16 Oktober 1994 
Setelah menentukan nomor klasifikasi, maka langkah selanjutnya adalah menentukan tajuk entri utama. Tajuk entri utama biasanya berwujud nama pengarang atau penanggung jawab kepengarangan, baik nama perseorangan maupun nama badan korporasi yang bertanggung jawab terhadap isi sebuah dokumen atau bahan pustaka. Namun, dalam hal tertentu, tajuk entri utama bisa berupa judul bahan pustaka tersebut.

Setelah tajuk entri utama ditentukan, maka langkah terakhir adalah pemberian satu huruf judul bahan pustaka. Tetapi dalam kondisi tertentu, pemberian ini diabaikan pada penggunaan SKPA.

Ketiga tahap ini nantinya menjadikan bahan pustaka mempunyai call number atau nomor panggil. Nomor panggil inilah yang nantinya ditempel pada punggung buku. Fungsi dari call number adalah untuk menentukan deret penjajaran bahan pustaka pada rak koleksi perpustakaan.

Tabel 3. Contoh Call Number di Perpustakaan Balai Arkeologi D.I Yogyakarta

\begin{tabular}{|c|c|c|c|}
\hline Judul Buku & Pengarang & $\begin{array}{c}\text { Nomor } \\
\text { Klas }\end{array}$ & $\begin{array}{l}\text { Nomor } \\
\text { Panggil }\end{array}$ \\
\hline $\begin{array}{l}\text { The Prehistory of } \\
\text { the Mind }\end{array}$ & Steven Mithen & 01 & $\begin{array}{c}01 \\
\text { Mit } \\
P\end{array}$ \\
\hline Borobudur & $\begin{array}{l}\text { Jacques } \\
\text { Dumarcey }\end{array}$ & 02.7 & $\begin{array}{l}02.7 \\
\text { Dum } \\
\text { B }\end{array}$ \\
\hline $\begin{array}{l}\text { Sejarah Arsitektur } \\
\text { Islam }\end{array}$ & Abdul Rochym & 03.1 & $\begin{array}{l}03.1 \\
\text { Roc } \\
\text { S }\end{array}$ \\
\hline $\begin{array}{l}\text { Antropologi } \\
\text { Budaya }\end{array}$ & H.R Warsito & 05 & $\begin{array}{c}05 \\
\text { War } \\
\text { A }\end{array}$ \\
\hline The Austronesians & Peter Bellwood & 06 & $\begin{array}{c}06 \\
\text { Bel } \\
\text { A }\end{array}$ \\
\hline $\begin{array}{l}\text { Clinically } \\
\text { Oriented Anatomy }\end{array}$ & Keith L Moore & 07 & $\begin{array}{c}07 \\
\text { Moo } \\
\mathrm{C}\end{array}$ \\
\hline $\begin{array}{l}\text { Berkala Arkeologi } \\
\text { XII Nopember } \\
1991\end{array}$ & $\begin{array}{l}\text { Balai Arkeologi } \\
\text { Yogyakarta }\end{array}$ & 09.1 & $\begin{array}{c}09.1 \\
\text { BA.XII } \\
\text { Nop.1991 }\end{array}$ \\
\hline
\end{tabular}

Sumber: Katalog Perpustakaan Balar D.I Yogyakarta

\section{METODE PENELITIAN}

Bentuk penelitian ini adalah deskriptif dengan menggunakan pendekatan kualitatif, yakni pendekatan dengan membuat gambarangambaran sifat sesuatu yang sedang berlangsung dengan tujauan agar objek dapat dibahas secara mendalam. Teknik pengumpulan data dilakukan dengan wawancara kepada pustakawan senior, terkait dengan penggunaan Sistem Klasifikasi Perpustakaan Arkeologi (SKPA). Selain wawancara, juga dilakukan pengamatan/observasi kepada subyek yang diteliti, sehingga subyek dengan sukarela memberi kesempatan kepada peneliti untuk mengamati proses yang terjadi. Studi literatur/bahan rujukan yang berisi tentang pedoman penggunaan SKPA di Perpustakaan Balai Arkeologi D.I Yogyakarta.

\section{HASIL DAN PEMBAHASAN}

Sistem klasifikasi mandiri atau khusus sebenarnya telah banyak digunakan di berbagai perpustakaan. Sebagai contoh Perpustakaan Kongres Amerika Serikat yang meggunakan notasi huruf atau lebih dikenal dengan Library of Congress System, dan Perpustakaan Badan Pengkajian dan Penerapan Teknologi yang mengadopsi sistem klasifikasi National Technical Information Services (NTIS). yang diterapkan di Perpustakaan U.S Departement of Commerce.

Bahkan sebagian besar penerapan sistem klasifikasi mandiri pada bagian pengolahan koleksi skripsi, tesis, deisertasi, mauapun laporan penelitian pada perpustakaan universitas. Hal ini lazim digunakan oleh perpustakaan, dikarenakan jenis koleksi yang membutuhkan perlakukan khusus dalam pengorganisasian koleksi. Sesuai penelitian skripsi oleh Noviani pada tahun 2013 yang mengkaji Pengaruh Sistem Klasifikasi Mandiri terhadap Hasil Temu Balik Pemustaka pada Layanan Skripsi dan Tugas Akhir Perpustakaan Sekolah Tinggi Islam Negeri Pekalongan (Noviani, 2013).

Pustakawan di Balai Arkeologi D.I Yogyakarta pada rentang tahun 1980 sampai dengan 1993 telah mencoba menggunakan sistem klasifikasi Dewey Decimal Classification/DDC Edisi 18 yang diterbitkan pada tahun 1971. Nomor kelas pada DDC Edisi 18 belum mengakomodir subyek klasifikasi pada bidang sejarah yang ada. Beberapa kendala yang dialami pustakawan dalam menggunakan 
DDC Edisi 18 dalam pengklasifikasian bidang arkeologi yaitu sebagai berikut:

a. Pengklasifikasian pada ilmu sejarah dan arkeologi masih bersifat umum pada kelas 900.

b. Belum adanya pengklasifikasian khusus pada bidang spesifikasi arkeologi, misalnya bidang epigrafi, arkeometri, etnoarkeologi, yang masih berkorelasi dengan ilmu arkeologi.

c. Pengklasifikasian kumpulan makalah yang diterbitkan oleh Ikatan Ahli Arkeologi Indonesia, misalnya Pekan Ilmiah Arkeologi, Diskusi Ilmiah Arkeologi, Evaluasi Hasil Penelitian Arkeologi jika diklasifikasikan dengan klasifikasi DDC tidak akan menjadi satu kelompok. Hal ini dikarenakan setiap tahun penyelenggaraan pertemuan ilmiah arkeologi akan berbeda subyek kajian utama dalam pertemuan tersebut.

d. Adanya terbitan laporan penelitian arkeologi tidak dapat terakomodir secara spesifik pada kelas 000 .

e. Pemustaka sangat kesulitan dalam melakukan penelusuran koleksi dengan sistem klasifikasi DDC.

f. Ruang penjajaran koleksi dan ruang pelayanan sirkulasi dan referensi masih menjadi satu ruangan.

Dalam penggunaan bagan SKPA (Tabel 2) terdapat beberapa kendala dalam menentukan nomor klasifikasi terhadap subyek atau jenis koleksi bahan pustaka yang hendak diklasifikasi. Disamping itu dengan adanya perkembangan ilmu arkeologi juga menambah kendala tersendiri. Beberapa kendala tersebut adalah:

\section{Pembagian kelas utama yang tumpang tindih}

Pada pembagian kelas utama yaitu kelas 04 Bidang ARKEOMETRI, penulis mencari beberapa literatur tentang kajian ilmu tersebut. Menurut Sudiono (1993), -bahwa ARKEOMETRI adalah gabungan dari berbagai disiplin ilmu (ilmu sosial dan eksak) yang secara metrik bertujuan memecahkan masalah yang muncul dalam rekonstruksi masa lampau kegiatan penelitian yang dititikberatkan pada masalah teknis dan laboratoris yang menunjang analisis penelitian.

Disiplin ilmu ini cenderung untuk kajian teknis analisis laboratoris yang bertujuan untuk mendukung data penelitian, baik penelitian prasejarah, klasik, maupun Islamkolonial. Analisis ini bermacam-macam, bisa analisis dating radio carbon, bahan penyusun keramik, geomorfologi, dan lain sebagainya.Untuk itu kelas utama ARKEOMETRI lebih baik dimasukkan ke dalam subkelas pada tiga bidang kelas utama yaitu Kelas Bidang Arkeologi Prasejarah, Klasik, maupun Islam-Kolonial.

Hal ini sebenarnya sudah disadari oleh pustakawan yang bertugas sebagai classifier, bahwa subyek ARKEOMETRI merupakan subkelas dan bukan kelas utama. Nomor klasifikasi pada kelas utama ARKEOMETRI pada akhirnya tidak digunakan dalam pengklasifikasian bahan pustaka sejak adanya penerapan SKPA.

\section{Pembagian subkelas yang salah}

Apabila dilihat pada pembagian tiga kelas bidang utama di atas, penulis melihat adanya ketidaksesuaian dalam membagi subkelas pada bidang tersebut. Misalnya pada Bidang Prasejarah terdapat subkelas IKONOGRAFI yang memuat subyek seni pada masa manusia purba. Hal ini tentu menjadi rancu, dikarenakan ikonografi itu sendiri lebih kepada Bidang Klasik, yaitu mengenai seni arca.

Ikonografi itu sendiri berasal dari kata ikon (icon) dan graphoo.Istilah ikon berasal dari bahasa Yunani, eikoon yang berarti bayangan, potret, gambar. Sedangkan kata graphoo artinya menulis, merinci.

Maulana (1997) menjabarkan bahwa ikonografi adalah rincian suatu benda yang menggambarkan tokoh dewa atau seseorang yang keramat dalam bentuk suatu lukisan, relief, arca atau benda lainnya, sedangkan bidang prasejarah bisa terdapat subyek kesenian, misalnya lukisan manusia purba di dinding gua, seni manik-manik, seni 
gerabah, dan lain-lain. Untuk itu, sebaiknya subkelas IKONOGRAFI pada kelas utama Bidang Arkeologi Prasejarah diganti dengan subkelas KESENIAN/BUDAYA.

\section{Inkonsistensi Pengklasifikasian}

Dalam penerapan nomor kelas 12 pada bidang SEJARAH sedikit mengalami kerancuan. Kajian subyek pada bahan pustaka yang memuat sejarah masa klasik terkandang terklasifikasi ke dalam kelas tersebut.

Belum lagi adanya kerancuan penomeran klasifikasi yang tidak lagi mengikuti aturan baku dari bagan SKPA. Misalnya pada buku yang berjudul, "Masa Akhir Majapahit : Girindrawardhana dan Permasalahannya", oleh classifier dikelaskan pada nomor 02.5. Padahal nomor subkelas ini adalah subyek TEKNOLOGI. Hal ini juga dikarenakan tidak adanya subkelas untuk subyek PEMERINTAHAN atau POLITIK pada bagan klasifikasi.

Contoh lainnya yaitu, buku "Tokoh Antagonis Darmo Gandhul: Tragedi Sosial Historis dan Keagamaan di Penghujung Kekuasaan Majapahit", yang dikelaskan pada nomor 02.2. Sedangkan pada bagan SKPA tahun 1994, nomor kelas 02.2 dipakai untuk subyek PEMUKIMAN dan bukan RELIGI. Seharusnya buku tersebut dikelaskan pada nomor 02.3 dengan subkelas RELIGI.

\section{Munculnya nomor klasifikasi baru}

Hasil pegamatan penerapan nomor klasifikasi bahan pustaka yang ada di rak koleksi, terdapat beberapa nomor klasifikasi baru yang digunakan oleh classifier dalam menentukan subyek atau disiplin ilmu. Sebagai contoh adalah sebagai berikut ini :

a. Judul buku "Sumba Religi dan Tradisi" muncul dengan nomor klasifikasi 01.7

b. Judul buku "Prasejarah Papua", muncul dengan nomor klasifikasi 01.8

c. Judul buku "Desawarnana", muncul dengan nomor klasifikasi 02.9

d. Judul buku "Islamic Art", muncul dengan nomor klasifikasi 03.8 e. Judul buku, "Banten sebelum Zaman Islam”, muncul dengan nomor klasifikasi 03.9.

Munculnya koleksi fiksi, juga menjadi masalah tersendiri dalam penentuan klasifikasi bahan pustaka. Hal ini dikarenakan pada bagan sistem SKPA belumlah mengakomodir jenis koleksi fiksi. Misalnya judul buku fiksi "Gajah Mada : Hamukti Palapa", diklasifikasi dengan kelas 16. Padahal dalam bagan sistem SKPA tidak terdapat nomor klasifikasi 16. Untuk itu, perlu adanya kajian dalam penambahan nomor klasifikasi baru.

\section{Perubahan subyek kelas utama pada bagan klasifikasi yang tidak tepat}

Seperti halnya sistem klasifikasi DDC yang terus menambah bagan kelas subyek ilmu, maka seharusnya sistem SKPA juga mengalami penambahan atau pergantian nomor kelas. Munculnya subyek ilmu Cultural Resource Management (CRM) pada akhir-akhir ini sudah diperhatikan oleh classifier di perpustakaan. Sehingga classifier mengklasifikasi subyek CRM ke dalam kelas 11. Dari hasil pengamatan pemasukkan subyek CRM ke kelas 11 sangatlah tidak tepat. Hal ini dikarenakan kelas 11 pada bagan sistem SKPA tahun 1994 sudah digunakan sebagai nomor klasifikasi terbitan yang berbentuk MAKALAH. Sehingga hal ini menjadi kerancuan tersendiri nantinya dalam pengklasifikasian bahan pustaka yang ada.

\section{Hilangnya beberapa subkelas}

Hasil pengamatan subkelas pada kelas 13 yang pada awalnya digunakan untuk koleksi Laporan Hasil Penelitian Arkeologi, Laporan Penelitian Arkeologi dan Berita Penelitian Arkeologi kini beralih ke dalam subkelas 10.5. Hal ini sebenarnya sudah tepat, karena tiga jenis koleksi tersebut termasuk dalam kategori koleksi laporan instansi yang dikelompokkan pada subkelas 10 dan bukan pada kelas 13. Untuk kelas 13, sekarang diisi dengan jenis koleksi laporan 
dari penelitian luar instansi, misalnya Fakultas Ilmu Budaya UGM dan lain-lain.

Adanya perkembangan disiplin ilmu dari subyek arkeologi, saran dari penulis dalam bagan SKPA dapat menambahkan nomor klasifikasi, baik kelas utama maupun subkelas. Hal ini dimaksudkan agar classifier tidak lagi mengalami kebingungan dalam penentuan nomor klasifikasi. Jika menggunakan sistem DDC Edisi ke 23 tentu tidak terjadi kendala, tetapi jika tetap menggunakan bagan SKPA maka perlu adanya perubahan dan penambahan kelas dan subkelas pada sistem klasifikasi tersebut. Adapun bagan SKPA yang diusulkan penulis dapat dilihat pada Tabel 4.

\section{Tabel 4.Bagan Pembaharuan Sistem Klasifikasi} Perpustakaan Arkeologi

01

$\begin{array}{ll} & \text { Arkeologi Prasejarah } \\ 01.1 & \text { Arsitektur } \\ 01.2 & \text { Pemukiman } \\ 01.3 & \text { Religi } \\ 01.4 & \text { Sosial Ekonomi } \\ 01.5 & \text { Teknologi }\end{array}$

02

01.5 Teknologi

Arkeologi Klasik

Arsitektur

02.2 Pemukiman

02.3 Religi

02.4 Sosial Ekonomi

02.5 Teknologi

02.6 Epigrafi/Paleografi (tulisan tangan kuno, prasasti)

$02.7 \quad$ Ikonografi

$02.8 \quad$ Kesenian/Budaya

02.9 Sistem Pemerintahan dan Politik

$02.10 \quad$ Militer

02.11 Sastra (kelaskan juga naskah kuno, babad dsb)

03

Arkeologi Islam - Kolonial

$03.1 \quad$ Arsitektur

03.2 Pemukiman

03.3 Religi

03.4 Sosial Ekonomi

03.5 Teknologi

03.6 Epigrafi/Paleografi (tulisan tangan kuno, prasasti)

03.7 Kesenian/Budaya

03.8 Sistem Pemerintahan dan Politik

03.9 Militer

03.10 Sastra (kelaskan juga naskah kuno, babad dsb) Cultural Resource Management (CRM)/Arkeologi Publik
05

06

07

08

08.1

08.2

08.3

08.4

08.5

08.6

08.7

08.8

09

09.1

09.2

09.3

09.4

10

10.1

10.2

10.3

10.4

10.5

10.6

10.7

10.8

10.9

11

11.1

11.2

11.3

11.4

11.5

11.6

11.7

12

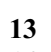

13

14

15

16
Etnoarkeologi (Jangan kela skan untuk Teori Antropologi dan Etnografi, kelaskan pada nomor kelas 07)

Biografi (Kelaskan disini biografi tokoh-tokoh dunia)

Metode/Teori/IImu Bantu Arkeologi

Kebudayaan

Peradaban Dunia

Kalimantan

Sunda, Bali, Jakarta

Irian, NTT, NTB

Jawa, Madura

Sulawesi

Sumatra

Indonesia Umum

Penerbitan Jurnal Ilmiah Berkala

Bidang Arkeologi

Bidang Ilmu Bantu

Majalah Ilmiah/Popular

Bulletin Ilmiah/Popular

Laporan Penelitian

Berita Penelitian Arkeologi

Laporan BPCB Yogyakarta

Laporan BPCB Jawa Tengah

Laporan BPCB Jawa Timur

Laporan Hasil Penelitian Arkeologi Balar Yogya

Laporan Hasil Penelitian Arkeologi (OV, ROD)

Laporan Penelitian Universitas

Laporan Penelitian Dinas

Laporan Puslit Arkenas

Kumpulan Makalah

PIA

AHPA

REMPA

EHPA

REHPA

DIA

Lain-Lain

Sejarah Umum dan Indonesia (Kelaskan juga

sejarah perkembangan sosial, budaya,

museum, ekonomi, militer dan politik)

Kamus

Ensiklopedi

Bibliografi

Bidang Hukum

Undang-Undang

Peraturan Pemerintah

Keputusan Presiden

Peraturan Menteri

Keputusan Menteri

Keputusan Bersama

Peraturan Daerah

Skripsi

Tesis

Desertasi

Fiksi (Kelaskan novel, legenda, dongeng, dII) 
Dengan adanya bagan SKPA yang baru ini, diharapkan pustakawan yang bekerja sebagai classifier dapat menentukan nomor klasifikasi secara tepat. Sehingga dalam temu kembali informasi oleh pemustaka, dapat dilakukan dengan efisien dan efektif.

\section{E. KESIMPULAN}

Kesimpulan dari hasil penelitian yang telah dilakukan tentang penerapan Sistem Klasifikasi Perpustakaan Arkeologi di Perpustakaan Balai Arkeologi D.I Yogyakarta adalah pembagian kelas utama yang tumpang tindih, pembagian subkelas yang salah, inkonsistensi pengklasifikasian, munculnya nomor klasifikasi baru, perubahan subyek kelas utama yang tidak tepat, dan hilangnya beberapa subkelas dalam penerapan SKPA. Adanya perkembangan disiplin ilmu arkeologi, maka perlu perubahan atau penambahan kelas utama dan subkelas pada bagan SKPA sesuai dengan perkembangan ilmu arkeologi.

\section{DAFTAR PUSTAKA}

Abd Rohim. (2010). Penerapan Sistem Klasifikasi National Technical Information Services (NTIS) di Badan Pengkajian dan Penerapan Teknologi (BPPT). Universitas Islam Negeri Syarif Hidayatullah, Jakarta.

Hamakonda, T. P. dan J. N. . T. (2006). Pengantar Klasifikasi Persepuluhan Dewey. Jakarta: Gunung Mulia.
Masruri, A. (2006). Teori dan Aplikasi DDC dalam Penentuan Nomor Klasifikasi Koleksi Perpustakaan : Sebuah Pengantar. FIHRIS : Jurnal Ilmu Perpustakaan Dan Informasi, Vol.I No.2 (Juli-Desember), 133-146.

Maulana, R. (1997). Ikonografi Hindu. Jakarta: Fakultas Sastra, Universitas Indonesia.

Noviani, M. (2013). Pengaruh Sistem Klasifikasi Mandiri Terhadap Hasil Temu Balik Pemustaka pada Layanan Skripsi dan Tugas Akhir Perpustakaan Sekolah Tinggi Islam Negeri Pekalongan. Universitas Diponegoro.

Sudiono. (1993). Orientasi Penelitian Arkeometri dalam PJPT II. In Kumpulan Makalah EHPA Yogyakarta, 25-30 Juli 1993 (pp. 1-15). Yogyakarta: IAAI.

Sutarno. (2006). Manajemen Perpustakaan Suatu Pendekatan Praktik. Jakarta: Sagung Seto.

Suwarno, W. (2007). Dasar-Dasar Ilmu Perpustakaan: Sebuah Pendekatan Praktis. Yogyakarta: Ar-ruzz Media.

Widodo, S. (1994). Sistem Klasifikasi dan Katalogisasi Perpustakaan Arkeologi. In Kumpulan Makalah EHPA Palembang, 1116 Oktober 1994 (pp. 1-2). Palembang: IAAI.

Yusup.Pawit M dan Yaya Suhendar. (2005). Pedoman Penyelenggaraan Perpustakaan Sekolah. Jakarta: Kencana. 